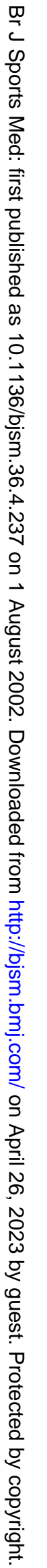


Revalidation

\section{Revalidation in sport and exercise medicine}

\author{
D A D Macleod, M E Batt, S Sheard
}

\section{The proposed annual appraisal of practitioners of sport and exercise medicine is outlined}

n 1999 the General Medical Council (GMC) of the United Kingdom agreed that "all doctors must be able to demonstrate regularly that they continue to be fit to practice in their chosen field". This process is termed revalidation. Doctors who complete revalidation will be granted a "licence to practice", affording them the rights and privileges currently associated with being included on the general register of the GM C.

Each individual doctor's revalidation will be reviewed every five years by two doctors and a single lay person. This team will be drawn from a local revalidation pool of trained people. Revalidation will be based on the contents of the individual doctor's revalidation portfolio. Each doctor's portfolio, irrespective of their specialty, will follow a standardised format. The relevant guidelines describing appropriate standards of practice will be drawn up by the Medical Royal Colleges. This immediately creates a challenge for sport and exercise medicine which does not have a single parent Medical Royal College and is not widely recognised as a specialty, although a small number of doctors have already been placed on the GMC specialist register.

The I ntercollegiate Academic Board of Sport and Exercise Medicine (IABSEM) is responsible to its parent M edical Royal Colleges and Faculties for setting standards in sport and exercise medicine and would seem to be the appropriate body to draw up relevant guidelines to meet revalidation standards.
Doctors who are al ready $\mathrm{M}$ embers or Fellows of a Faculty or Medical Royal College recognised by the Academy of Medical Royal Colleges will be able to obtain revalidation with the support of their parent college. All doctors who practice sport and exercise medicine on either a part time or full time basis will have to meet all the GMC requirements. There are many doctors in the United Kingdom who are independent practitioners and currently practice sport and exercise medicine without being $\mathrm{Mem}$ bers or Fellows of a Medical Royal College or Faculty. It will be particularly important for this group of sport and exercise medicine practitioners to ensure that they undergo annual appraisal and are in a secure position to meet the requirements of revalidation.

We here outline the contents of the revalidation portfolio recommended by the GMC. Establishing a portfolio and preparing for annual appraisal will become an increasingly important aspect of the professional lifestyle of all doctors.

The revalidation folder recommended by the GMC is divided into four sections. ${ }^{2}$

\section{SECTION 1: YOUR PERSONAL AND REGISTRATION DETAILS}

This section will record personal biographical and educational details, including your current GM C number.
SECTION 2: WHAT YOU DO

This section will describe what you do and where you do it. It must cover all aspects of your medical practice, paid or voluntary, including private practice, insurance and medicolegal work, teaching, research, administration, and management. This section should give a clear outline of your casel oad and case-mix in all aspects of your clinical practice. It should include a job description and role profile where available.

\section{SECTION 3: INFORMATION ON YOUR PRACTICE}

This section will be based on the GM C publication Good medical practice and will require careful preparation and annual review to ensure its accuracy. ${ }^{3}$

The portfolio should show good professional standards of clinical care, record keeping-for example, contemporaneous, legible, and signed notes-and availability to patients including out of hours and when dealing with emergencies.

You will be expected to demonstrate that you are maintaining and developing good standards of clinical practice by undertaking audits and showing how the audits have influenced your practice. You will be expected to record adverse clinical events and how they were resolved. All complaints should also be documented and their outcome recorded.

Communication skills will be assessed by administration of patient surveys, the results of which will be incorporated in the portfolio. Sport and exercise medicine practitioners involved with a team

Section 3: Information on your practice

- Good professional practice

- Maintaining good clinical practice

- Relations with patients

- W orking with colleagues

- Teaching and training

- Honesty

- Health 
or group of athletes may find that surveys of the manager, coach, or sports participant for whom they are responsible will be expected.

You must record continuing professional development covering all aspects of your professional activities as outlined in Section 2 of your folder. The Academy of Medical Royal Colleges has issued a framework on this aspect of the portfolio. ${ }^{4}$

The Academy believes its framework will improve the safety and quality of medical practice by encouraging life long learning and making transparent the processes required for successful implementation of continuing professional development and audit.

The GM C places great emphasis on the ability of every doctor to work effectively in teams with colleagues, nurses, professions allied to medicine, clerical staff, and other professionals as well as lay people. This includes placing responsibility on colleagues to be aware of each other's standards of practice, conduct, or health if they may in any way be putting patients at risk.

Any doctor who teaches or trains junior medical staff, or other professionals, will be expected to show a commitment to developing educational standards and recording feedback on the teaching programmes in which they are involved.

Good medical practice also identifies honesty in clinical, research, and financial matters as being criteria against which revalidation will be measured. This includes honesty in writing reports and in the provision of references.

Finally this section of the revalidation portfolio requires the doctor to confirm that his or her own health, whether physical or psychological, is such that they are fit to practice in their chosen field(s).
SECTION 4: APPRAISAL

Mandatory annual appraisal of all aspects of every doctor's practice will be the basis of the revalidation process. The quality of the annual appraisal should highlight deficiencies or potential problems that may restrict or prevent revalidation, thereby giving the doctor concerned the opportunity to ensure that they are addressed before any subsequent appraisal.

Section 2 of the revalidation folder will outline all aspects of medical practice for which information must be recorded in Section 3.

The person to be appraised will be expected to ensure that their folder is accurate and up to date. The appraiser, who would normally be appointed by either a primary health care or employing hospital trust, would be expected to ensure that appropriate audits or surveys of the doctor's team working and communication skills have been completed.

The appraiser would be a doctor trained and experienced in this aspect of maintaining professional standards of practice. The appraisal interview will become a crucial component of every doctor's professional development and will be based on a $360^{\circ}$ review of every aspect of a doctor's practice. ${ }^{5}$

At the end of the interview the doctor and his or her appraiser should record the outcome, highlighting any areas of concern that may interfere, in due course, with revalidation. Potential solutions for any problems should be outlined. Significant concerns identified by an appraiser should be forwarded to the relevant trust or other appropriate bodies.

\section{CONCLUSION}

All doctors involved in sport and exercise medicine on a full or part time basis need

\section{Preparing for appraisal}

- How good a doctor am I?

- How well do I perform?

- How up to date am I?

- How well do I work in a team?

- What resources and support do I need?

- How well am I meeting my service objectives?

- W hat are my development needs?

to establish a revalidation portfolio as outlined above and identify how their annual appraisal will take place.

Br J Sports M ed 2002;36:237-238

Authors' affiliations

D A D Macleod, Intercollegiate Academic Board of Sport and Exercise M edicine, Edinburgh, Scotland, UK

M E Batt, C entre for Sports M edicine, University Hospital, Department of O rthopaedic and Accident Surgery, Q ueens M edical C entre, N ottingham N G 7 2UG, UK

S Sheard, BMI Health Services, G reyfriars, 10

Q ueen Victoria Road, Coventry CV1 3PJ, UK

Correspondence to: Dr Macleod, Chairman of the Intercollegiate Academic Board of Sport and Exercise M edicine, $\mathrm{N}$ icolson Street, Edinburgh EH8 9DW, Scotland, UK; y.gilbert@rcsed.ac.uk

\section{REFERENCES}

1 General Medical Council. Revalidating doctors. London: General M edical Council, 2000

2 General Medical Council. Pilot revalidation folder and piloting guidance. London: General M edical Council, 2001.

3 General Medical Council. Good medical practice. 3 rd ed. London: G eneral M edical Council, 2000

4 Academy of Medical Royal Colleges and their Faculties. A Framework for Continuing Professional Development. London: Academy of Medical Royal Colleges and their Faculties, 2001

5 J King. $360^{\circ}$ appraisal. BMJ

2002;324:s195. 